\title{
KARAKTERISASI KARBON AKTIF KOMERSIAL SERTA APLIKASINYA SEBAGAI ADSORBEN ION TIMBAL(II) DAN KROM(III)
}

\author{
Ni Ayu Putu Tejawati*, Manuntun Manurung dan Oka Ratnayani \\ Program Studi Kimia FMIPA Universitas Udayana, Bukit Jimbaran, Badung, Bali 80361 \\ *E-mail: putuayutj@yahoo.com
}

\begin{abstract}
ABSTRAK
Pada penelitian ini dilakukankarakterisasi karbon aktif komersial serta aplikasinya sebagai adsorben $\mathrm{Pb}$ (II) dan Cr(III). Penelitian ini bertujuan untuk mengetahui kualitas dari karbon aktif komersial berdasarkan SNI (Standar Nasional Indonesia) dibandingkan dengan karbon aktif komersial yang diaktifkan kembali dengan pemanasan pada suhu $600^{\circ} \mathrm{C}$ selama 2 jam. Hasil penelitian menunjukkan, nilai kadar air adalah 6,8\%, kadar zat menguap 13,22\%, kadar abu total $1,9 \%$ dan kadar karbon terikat sebesar 79,1\%. Bilangan iodin 774,2159 mg/g dan luas permukaan $8,9400 \mathrm{~m}^{2 /} \mathrm{g}$. Dengan pemanasan karbon aktif pada suhu $600^{\circ} \mathrm{C}$ selama 2 jam, bilangan iodin naik menjadi 864,7238 $\mathrm{mg} / \mathrm{g}$ dan luas permukaan karbon aktif 9,2511 $\mathrm{m}^{2 /} \mathrm{g}$. Kapasitas Adsorpsi karbon aktif komersial terhadap $\mathrm{Pb}(\mathrm{II})$ adalah $0,3438 \mathrm{mg} / \mathrm{g}$ dan $\mathrm{Cr}$ (III) $0,1861 \mathrm{mg} / \mathrm{g}$, sedangkan karbon teraktivasi panas kapasitas adsorpsinya adalah $0,6775 \mathrm{mg} / \mathrm{g}$ untuk $\mathrm{Pb}(\mathrm{II})$ dan $0,3033 \mathrm{mg} / \mathrm{g}$ pada $\mathrm{Cr}(\mathrm{III})$.
\end{abstract}

Kata kunci : $\quad$ karbon aktif komersial, $\mathrm{Pb}(\mathrm{II}), \mathrm{Cr}(\mathrm{III})$

\section{ABSTRACT}

This study is about the characterization of commercial activated carbon and its application as adsorbent for $\mathrm{Pb}(\mathrm{II})$ and $\mathrm{Cr}(\mathrm{III})$. This research aimed to find out the quality of commercial activated carbon based on the Indonesian National Standard (SNI 06 - 3730 - 1995) and its capacity for adsorbing $\mathrm{Pb}$ (II) and $\mathrm{Cr}$ (III), compared to the physically reactivated commercial carbon by heating at a temperature of $600^{\circ} \mathrm{C}$ for 2 hours. The results showed that the commercial activated carbon contained $6.8 \%$ of moisture, $13.22 \%$ of volatile matter, $1.9 \%$ of total ash and $79.1 \%$ of fixed carbon. The iodine number of commercial activated carbon was $774.2159 \mathrm{mg} / \mathrm{g}$, and after the carbon was reactivated physically the number increased to $864.7238 \mathrm{mg} / \mathrm{g}$. Similarly, the surface area of the activated carbon was $8.9400 \mathrm{~m}^{2} / \mathrm{g}$ and after the carbon reactivation was $9.2511 \mathrm{~m}^{2} / \mathrm{g}$. Furthermore, the adsorption capacity of activated carbon for $\mathrm{Pb}$ (II also improved from $3.4384 \mathrm{mg} / \mathrm{g}$ to $6.7712 \mathrm{mg} / \mathrm{g}$ and for $\mathrm{Cr}$ (III) from 1,8609 mg/g to $3.0340 \mathrm{mg} / \mathrm{g}$.

Keywords : commercially activated carbon, $\mathrm{Pb}(\mathrm{II}), \mathrm{Cr}(\mathrm{III})$

\section{PENDAHULUAN}

Limbah logam berat bila dibuang ke perairan tanpa pengolahan akan mencemari lingkungan dan dapat membahayakan kehidupan mahluk hidup, diantaranya timbal dan krom. Logam timbal berasal dari buangan industri metalurgi, yang bersifat racun dalam bentuk $\mathrm{Pb}$ arsenat. Di dalam tubuh manusia, timbal mengakibatkan terhambatnya aktifitas enzim yang terlibat dalam pembentukan hemoglobin yang dapat menyebabkan penyakit anemia (Marganof, 2003). Untuk menghindari keracunan dari logam ini, batas maksimum timbal dalam makanan laut yang ditetapkan oleh Departemen Kesehatan RI dan FAO adalah sebesar 2,00ppm. Pada organisme air kadar maksimum Timbal yang aman dalam air adalah sebesar $50 \mathrm{ppb}$ (Hutagalung, 1984).

Sumber utama pencemaran krom ke lingkungan adalah dari pembakaran batu bara dan minyak bumi. Krom termasuk logam berat yang mempunyai toksisitas yang tinggi. Keracunan akut disebabkan oleh ion krom $\left(\mathrm{Cr}^{3+}\right.$ dan $\mathrm{Cr}^{6+)}$ ditandai dengan kecenderungan terjadinya pembengkakan pada hati.

Berdasarkan standar Departemen

Kesehatan RI tahun 2010 No. 492/MENKES /Per/IV/2010 kadar maksimal krom pada air minum adalah $0,05 \mathrm{mg} / \mathrm{L}$ sedangkan menurut keputusan Menteri Negara Lingkungan Hidup.Tanggal 4 Juli 2007 No. 10 Tahun 2007 kadar maksimal krom pada air limbah adalah 1 $\mathrm{mg} / \mathrm{L}$. 
Karbon aktif merupakan karbon yang tidak berbentuk yang diolah secara khusus untuk menghasilkan luas permukaan yang besar, yaitu antara 300-2000 $\mathrm{m}^{2} / \mathrm{g}$. Arninda (2015) melakukan penelitian terhadap karbon aktif dari kulit pisang kepok, yang digunakan untuk mengadsorpsi ion $\mathrm{Pb}$ (II) dan ion $\mathrm{Cr}$ (III). Kapasitas adsorpsi ion $\mathrm{Pb}(\mathrm{II})$ adalah 13,5071 $\mathrm{mg} / \mathrm{g}$ dan $8,0490 \mathrm{mg} / \mathrm{g}$ untuk ion Cr(III). Sulfikar (2015) juga melakukan penelitian terhadap kapasitas adsorpsi dari karbon aktif ijuk pohon aren terhadap ion $\mathrm{Pb}^{2+}$ dengan nilai kapasitas adsorpsi sebesar $6,81 \mathrm{mg} / \mathrm{g}$.

Di pasaran berbagai jenis karbon aktif komersial ditawarkan kepada konsumen, salah satunya karbon aktif komersial import. Menurut SNI 06-3730-1996 tahun 1995 kadar air maksimal 15\%, kadar abu maksimal 10\%, kadar zat menguap maksimal 25\%, kadar karbon terikat minimal $65 \%$ dan daya serap terhadap iodin minimal $750 \mathrm{mg} / \mathrm{g}$. Pada penelitian ini dipelajari sifat fisik dan kimia dari salah satu karbon aktif komersial yang disesuaikan dengan prosedur SNI. Selain itu karbon aktif komersial ini diaktivasi secara fisika pada suhu $600^{\circ} \mathrm{C}$ selama 2 jam dan selanjutnya dipelajari kemampuan adsorpsinya terhadap ion $\mathrm{Pb}$ (II) dan Cr(III).

\section{MATERI DAN METODE}

\section{Bahan}

Bahan-bahan kimia yang digunakan dalam penelitian ini yaitu; karbon aktif komersial, kalium iodida, iodium, aquades, natrium tiosulfat $\left(\mathrm{Na}_{2} \mathrm{~S}_{2} \mathrm{O}_{3}\right)$, larutan kanji, $\mathrm{H}_{3} \mathrm{PO}_{4}, \mathrm{HNO}_{3}, \mathrm{KBr}$, aquades, biru metilen, $\mathrm{CrCl}_{3} \cdot 6 \mathrm{H}_{2} \mathrm{O}$ dan $\mathrm{Pb}\left(\mathrm{NO}_{3}\right)_{2}$.

\section{Peralatan}

Peralatan yang digunakan dalam penelitian ini yaitu neraca analitik, oven, desikator, cawan, tanur, gelas beker, erlenmeyer, pipet volume, pipet tetes, batang pengaduk, labu ukur, pemanas, seperangkat alat titrasi, gelas ukur, filler, pompa hidrolik, tabung setrifugal, FTIR, spektrofotometer UV-Vis dan AAS.

\section{Cara Kerja \\ Preparasi Sampel}

Karbon aktif komersial digerus dengan mortar dan diayak dengan ayakan $250 \mu \mathrm{m}$ dan tertahan pada $106 \mu \mathrm{m}$. Serbuk karbon yang tertahan pada $106 \mu \mathrm{m}$ ini kemudian ditimbang untuk penelitian selanjutnya.

\section{Aktivasi Fisika Karbon Aktif}

Ditimbang sebanyak 10 gram karbon aktif komersial, kemudian dimasukkan ke dalam tanur pada suhu $600^{\circ} \mathrm{C}$ dan dipanaskan selama 2 jam. Setelah itu karbon aktif komersial ini disimpan dan digunakan pada prosedur selanjutnya.

\section{Penentuan Kadar Air}

Pertama-tama ditimbang 5 gram karbon aktif komersial, kemudian dikeringkan pada oven dengan suhu $105{ }^{\circ} \mathrm{C}$ sampai beratnya konstan $( \pm 1$ jam). Selanjutnya karbon aktif ini dimasukkan ke dalam desikator sampai beratnya konstan, kemudian ditentukan kadar air (KA) dalam persen $(\%)$.

\section{Penentuan Kadar Zat Menguap}

Cawan berisi karbon aktif yang kadar airnya sudah ditetapkan dimasukkan dalam tanur pada suhu $900^{\circ} \mathrm{C}$ selama 15 menit. Selanjutnya cawan dimasukkan dalam desikator sampai beratnya konstan dan ditimbang.

\section{Penentuan Kadar Abu}

Cawan yang sudah berisi karbon aktif yang kadar air dan kadar zat menguapnya sudah ditetapkan, lalu di letakkan dalam tanur, perlahan-lahan dipanaskan mulai dari suhu kamar sampai $800^{\circ} \mathrm{C}$ selama $1 \mathrm{jam}$. Selanjutnya didinginkan dalam desikator sampai beratnya konstan kemudian ditimbang bobotnya.

\section{Penetapan Kadar Karbon Terikat}

Kadar karbon terikat adalah fraksi karbon yang terikat dalam ruangan selain fraksi air, zat menguap dan abu. Kadar karbon terikat diperoleh dari selisih persentase total dengan jumlah persentase kadar air, kadar zat menguap, dan kadar abu total dari karbon aktif.

\section{Karakterisasi Karbon Aktif Dengan FTIR \\ Untuk mengkarakterisasi gugus fungsi karbon aktif komersial digunakan spektrofotometer infra merah dengan metode pellet $\mathrm{KBr}$. Pertama sampel karbon aktif sebanyak $2 \mathrm{mg}$ dicampur dengan $100 \mathrm{mg}$ serbuk kering $\mathrm{KBr}$ dan ditumbuk hingga halus. Campuran tersebut kemudian dimampatkan dalam sebuah cetakan menggunakan pompa hidrolik sehingga membentuk pellet. Kemudian pellet ini dianalisis dengan spektrofotometer infra merah.}




\section{Daya Serap Karbon Aktif Terhadap Iodin}

Sebanyak 0,5 gram karbon aktif yang belum dan sudah diaktivasi dimasukkan ke dalam erlenmeyer yang tertutup. Kemudian dimasukkan $25 \mathrm{ml}$ larutan iodin $0,125 \mathrm{~N}$ dan diaduk selama 15 menit dan disimpan selama 2 jam. Larutan ini disaring dan kemudian dipipet $10 \mathrm{ml}$ lalu dimasukkan ke dalam erlenmeyer. Larutan ini dititrasi dengan natrium tiosulfat sampai warna kuning pada larutan mulai samar. Setelah itu ditambahkan amilum $1 \%$ sebagai indikator dan larutan kemudian dititrasi kembali hingga warna biru tua menjadi warna bening. Penentuan daya serap karbon aktif terhadap iodin dilakukan pengulangan sebanyak 3 kali dan dihitung volume natrium tiosulfat yang digunakan (ASTM D4607-94).

\section{Penentuan Panjang Gelombang Maksimum Biru Metilen}

sebanyak $10 \mathrm{ml}$ larutan standar biru metilen 20 ppm diukur absorbansinya pada panjang gelombang antara $400-700 \mathrm{~nm}$ pada spektrofotometri UV-Vis. Kemudian larutan standar biru metilen $0,1,2,3$, dan 4 ppm diukur absorbansinya pada panjang gelombang maksimum. Selanjutnya dibuat kurva kalibrasi standar biru metilen.

\section{Penentuan Luas Permukaan Karbon Aktif}

Sebanyak 0,5 gram karbon aktif ditambahkan ke dalam $20 \mathrm{ml}$ larutanbiru metilen $50 \mathrm{ppm}$, lalu diaduk dengan variasi waktu kontak 10, 20, 30,40,50, dan 60 menit. Larutan ini lalu disaring dengan kertas saring dan filtratnya dianalisis dengan spektrofotometri UV-Vis pada panjang gelombang maksimum. Absorbansi yang diperoleh dimasukkan ke dalam persamaan regresi linier biru metilen, sehingga diperoleh konsentrasi biru metilen dalam filtrat.

\section{Penentuan Kurva Standar Pb(II) dan Cr(III)} Larutan standar $\mathrm{Pb}$ (II) dan $\mathrm{Cr}(\mathrm{III})$ dengan konsentrasi 0,5 , 10, dan 15 ppm diukur pada AAS dengan panjang gelombang 217,0 nm untuk $\mathrm{Pb}(\mathrm{II})$ dan $357,9 \mathrm{~nm}$ untuk $\mathrm{Cr}$ (III). Selanjutnya dibuat kurva kalibrasi yang merupakan plot antara intensitas dengan konsentrasi.

\section{Penentuan Waktu SetimbangPb(II) dan Cr(III)}

Sebanyak 25 ml larutan $\mathrm{Pb}(\mathrm{II})$ danCr(III) dengan konsentrasi 15 ppm dimasukkan ke dalam labu erlenmeyer. Kemudian ditambahkan 0,5 gram karbon yang belum diaktivasi dan yang teraktivasi ke dalam masing-masing larutan. Campuran dikocok menggunakan shaker dengan variasi waktu kontak 30,60, 90, 120, dan 150 menit. Campuran lalu disaring dengan kertas saring biasa untuk memperoleh filtratnya. Setelah itu diukur absorbansianya dengan AAS untuk mengetahui banyaknya adsorbat yang tersisa dalam larutan.

\section{Penentuan Kapasitas Adsorpsi Ion Pb(II) dan Cr(III)}

Sebanyak $25 \mathrm{ml}$ larutan ion $\mathrm{Pb}(\mathrm{II})$ dan $\mathrm{Cr}$ (III) dengan konsentrasi 5, 10, 15, dan 20 ppm, ditambahkan 0,5 gram karbon aktif yang belum diaktivasi dan yang teraktivasi. Tiap-tiap campuran dikocok dengan shaker selama waktu setimbang, kemudian disaring dengan kertas saring biasa.Selanjutnya diukur absorbansinya dengan AAS sehingga kapasitas adsorpsi dan pola isoterm adsorpsinya dapat ditentukan.

\section{HASIL DAN PEMBAHASAN}

\section{Karakterisasi karbon aktif komersial}

Karakterisasi karbon aktif komersial ini dilakukan sesuai prosedur SNI 06 - 3730 - 1995 tentang persyaratankarbonaktifteknis. Beberapa parameter uji yang dianalisis meliputi kadar air, kadar zat menguap, kadar abu, dan kadar karbon terikat. Hasil dari penelitian yang diperoleh disajikan dalam Tabel 1.

Secara keseluruhan karbon aktif ini telah memenuhi persyaratan kualitas karbon aktif, karena kadaraair, kadar zat menguap, kadaraabu total dan kadar karbon terikat seluruhnya sesuai dengan Standar Nasional Indonesia. Hal ini berarti secara teknis karbon aktif komersial yang dikarakterisasi telah memenuhi standar SNI.

\section{Tabel 1 Parameter Fisikokimia Karbon Aktif} Komersial

\begin{tabular}{cc}
\hline Parameter & Hasil \\
\hline Kadar air & $6,8 \%$ \\
Kadar zat menguap & $13,22 \%$ \\
Kadar abu total & $1,9 \%$ \\
Kadar karbon terikat & $79,1 \%$ \\
\hline
\end{tabular}




\section{Identifikasi Gugus Fungsi}

Pada penelitian ini telah dilakukan karakterisasi karbon aktif komersial dan yang teraktivasi pada suhu $600^{\circ} \mathrm{C}$ selama 2 jam dengan Spektrofotometer FTIR. Berikut ini ditampilkan gambar spektra IR dari karbon yang tidak diaktivasidan gambar spektra IR dari karbon yang teraktivasi.

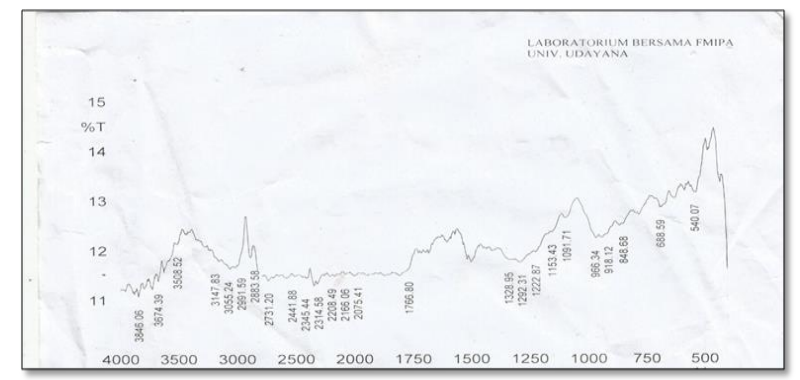

Gambar 1 Spektra karbon aktif komersial tanpa aktivasi

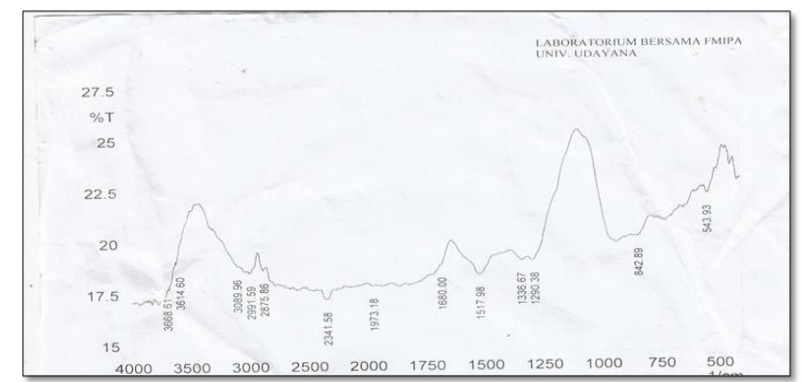

Gambar 2 Spektra karbon aktif komersial dengan aktivasi fisika pada suhu $600^{\circ} \mathrm{C}$

Hasil identifikasi dari karbon aktif komersial dan yang teraktivasi menunjukkan bahwa karbon aktif ini mengandung gugus aromatik, hidrokarbon serta gugus $\mathrm{OH}$. Namun jika dilihat dari kedua spektra karbon aktif adanya aktivasi tidak memberikan perubahan yang signifikan terhadap gugus-gugus fungsi yang terkandung pada kedua karbon aktif. Gugus-gugus fungsi yang muncul pada spektra karbon aktif komersial dan yang teraktivasi sama, hanya saja bilangan gelombangnya berbeda. Aktivasi fisika menyebabkan terjadinya pergesaran lingkungan kimia karbon aktif. Gugus fungsi $\mathrm{OH}$ mengalami pergeseran bilangan gelombang dan semakin tajam setelah mengalami aktivasi.Sedangkan untuk pita serapan yang melebar pada karbon aktif sebelum teraktivasidiperkirakan karena masih banyaknya uap air pada karbon. Kandungan uap air yang banyak dapat mengurangi jumlah pori- pori pada luas permukaan. Jadi, perbedaan tersebut diperkirakan bersesuaian dengan kemampuan karbon aktif dalam mengadsorpsi lebih tinggi pada karbon aktif yang teraktivasi.

\section{Pengaruh aktivasi fisika terhadap sifat karbon aktif komersial}

Untuk mengetahui pengaruh aktivasi fisika ini digunakan parameter bilangan iodin, luas permukaan dan kapasitas adsorpsi karbon aktif terhadap kation $\mathrm{Pb}$ dan $\mathrm{Cr}$. Dari perhitungan yang telah dilakukan diperoleh nilai bilangan iodin dan luas permukaan karbon aktif seperti pada Tabel 2 berikut.

Dari penelitian ini dapat dilihat bahwa karbon aktif komersial yang teraktivasi fisika memiliki nilai bilangan iodin dan luas permukaan yang lebih besar daripada yang tidak diaktivasi fisika. Hal ini disebabkan aktivasi fisika dapat menghilangkan pengotor sehingga dapat memperluas bidang penyerapan karbon aktif, yang mengakibatkan jumlah pori-pori yang ada pada karbon aktif semakin banyak sehingga daya serapnya terhadap iodin dapat semakin meningkat.

\section{Kapasitas Adsorpsi Karbon Aktif}

Dalam menentukan kapasitas adsorpsi karbon aktif terlebih dahulu ditentukan pola isoterm adsorpsinya. Perhitungan yang dilakukan pada penelitian ini digunakan pola isoterm adsorpsi Langmuir yang diperoleh dengan menghubungkan antara konsentrasi adsorbat pada saat kesetimbang-an $(\mathrm{Ce})$ serta konsentrasi adsorbat saat ke-setimbangan per banyaknya zat yang terserap per satuan berat adsorben. Penentuan Isoterm adsorpsi Freundlich dapat diperoleh dengan mem-plotkan antara $\ln (\mathrm{Ce})$ dan $\ln \mathrm{m}$. Dari kurva isoterm adsorpsi diketahui nilai koefisien korelasi $\left(\mathrm{R}^{2}\right)$ pada karbon aktif komersial dengan pola isoterm adsorpsi langmuir adalah 0,991 untuk ion $\mathrm{Pb}$ (II) dan 0,962 untuk Cr (III). Selanjutya untuk pola isoterm adsorpsi Freundlich adalah 0,165 untuk ion $\mathrm{Pb}$ (II) dan 0,031 untuk $\mathrm{Cr}$ (III). Pada karbon aktif teraktivasi nilai koefisien korelasi $\left(\mathrm{R}^{2}\right)$ pola isoterm adsorpsi langmuir sebesar 0,996 untuk ion $\mathrm{Pb}$ (II) dan 0,986 untuk $\mathrm{Cr}$ (III). Pada pola isoterm adsorpsi freundlich adalah 0,519 ion $\mathrm{Pb}$ (II) dan 0,135 untuk Cr (III). 
Tabel 2 Nilai bilangan iodine dan luas permukaan karbon aktif

\begin{tabular}{ccc}
\hline $\begin{array}{c}\text { Karbon } \\
\text { Aktif }\end{array}$ & $\begin{array}{c}\text { Bilangan } \\
\text { iodin } \\
(\mathrm{mg} / \mathrm{g})\end{array}$ & $\begin{array}{c}\text { Luas } \\
\text { permukaan } \\
\left(\mathrm{m}^{2} / \mathrm{g}\right)\end{array}$ \\
\hline Komersial & 774,2159 & 8,9400 \\
Teraktivasi & 864,7238 & 9,2511 \\
\hline
\end{tabular}

Persamaan regresi linier pada kurva isoterm langmuir dapat dihitung kapasitas adsorpsi dari karbon aktif komersial. Untuk mengetahui kapasitas adsorpsi karbon aktif seperti pada Tabel 3.

Tabel 3 Kapasitas adsorpsi karbon aktif

\begin{tabular}{cccc}
\hline $\begin{array}{c}\text { Karbon } \\
\text { aktif }\end{array}$ & Kation & $\begin{array}{c}\text { Kapasitas } \\
\text { adsorpsi } \\
(\mathrm{mg} / \mathrm{g})\end{array}$ & $\begin{array}{c}\text { Energi } \\
\text { adsorpsi } \\
(\mathrm{kJ} / \mathrm{mol})\end{array}$ \\
\hline $\begin{array}{c}\text { Karbon } \\
\text { aktif }\end{array}$ & $\mathrm{Pb}$ (II) & 0,3438 & 3,6391 \\
$\begin{array}{c}\text { komersial } \\
\text { Karbon }\end{array}$ & 0,1861 & 0,2748 \\
$\begin{array}{c}\mathrm{Pb} \text { (II) } \\
\text { aktif }\end{array}$ & 0,6775 & 4,4893 \\
komersial & & 0,3033 & 2,2393 \\
teraktivasi & & & \\
\hline
\end{tabular}

Kapasitas adsorpsi terbesar pada penelitian ini terdapat pada karbon aktif yang diaktivasi fisika dalam penyerapan ion $\mathrm{Pb}(\mathrm{II})$. Sedangkan untuk penyerapan ion $\mathrm{Cr}$ (III) lebih kecil di-bandingkan dengan ion $\mathrm{Pb}$ (II). Pada proses adsorpsi ion $\mathrm{Pb}$ (II) mempunyai jari-jari yang lebih besar, yang dapat membentuk molekul hidrasi yang lebih kecil sehingga dapat mengisi semua jenis pori yang terdapat pada karbon aktif baik berukuran mikropori, mesopori maupun makro-pori. Ukuran molekul hidrasi $\mathrm{Cr}$ (III) lebih besar karena memiliki jari-jari ion yang lebih kecil, sehingga $\mathrm{Cr}$ (III) kemungkinan hanya bisa mengisi pori yang berukuran mesopori dan makropori saja, sedangkan mikropori tidak bisa dimasuki oleh $\mathrm{Cr}$ (III) sehingga jumlah ion yang teradsorpsi berkurang (Atandawu, 2013).

Energi adsorpsi yang diperoleh dari rumus $\mathrm{Ea}=$ R.T.ln $\mathrm{k}$, nilainya kurang dari 20 $\mathrm{kJ} / \mathrm{mol}$ sehingga adsorpsi yang terjadi pada penelitian ini adalah adsorpsi fisik. Ini sesuai dengan pernyataan yang dikemukakan oleh Adamson (1990) dimana adsorpsi fisika energi adsorpsinya $<20 \mathrm{~kJ} / \mathrm{mol}$, sedangkan adsorpsi kimia energi adsorpsinya lebih tingggi $(>20$ $\mathrm{kJ} / \mathrm{mol}$ ).

\section{SIMPULAN DAN SARAN}

\section{Simpulan}

Berdasarkan penelitian yang telah dilakukan dapat disimpulkan sebagai berikut :

1. Karbon aktif komersial sudah memenuhi standar SNI $06 \quad-3730$ 1995tentangkualitas karbon aktifteknis. Dimana kadar air sebesar 6,8 \%, kadar zat menguap sebesar $13,22 \%$, kadar abu sebesar $1,9 \%$ dan kadar karbon terikat sebesar $79,1 \%$.

2. Aktivasi fisika dengan pemanasan pada suhu $600^{\circ} \mathrm{C}$ selama 2 jam menyebabkan nilai bilangan iodin karbon aktif komersial yang awalnya sebesar $774,2159 \mathrm{mg} / \mathrm{g}$ naik menjadi $864,7238 \mathrm{mg} / \mathrm{g}$. Luas permukaan karbon aktif komersial dari 8,9400 naik menjadi $9,2511 \mathrm{~m}^{2} / \mathrm{g}$.

3. Kapasitas adsorpsi karbon aktif komersial terhadap ion $\mathrm{Pb}(\mathrm{II})$ dan $\mathrm{Cr}$ (III) sebesar $0,3438 \mathrm{mg} / \mathrm{g}$ dan $0,1861 \mathrm{mg} / \mathrm{g}$ sedangkan karbon aktif komersial teraktivasi sebesar $0,6775 \mathrm{mg} / \mathrm{g}$ dan $0,3033 \mathrm{mg} / \mathrm{g}$.

\section{Saran}

1. Perlu dikaji lagi aktivitas dari karbon aktif komersial ini pada suhu yang lebih tinggi atau perpaduan aktivasi fisika dan kimia.

2. Perlu dikaji kemampuannya dalam menyerap zat warna

\section{UCAPAN TERIMAKASIH}

Penulis mengucapkan terimakasih kepada LPPM Unud atas bantuan dana yang diberikan melalui hibah penelitian unggulan perguruan tinggi tahun ajaran 2016 dengan kontrak nomor : 641-22/UN14.2/PNL.01.03.00/2016.

\section{DAFTAR PUSTAKA}

Adamson, A.W., 1990, Physical Chemistry on Surface, $4^{\text {th }}$ Ed, Jhon Willey \& Sons, New York.

Arninda, A., 2015, Adsorpsi Ion Logam $\mathrm{Pb}$ (II) dan $\mathrm{Cr}(\mathrm{III})$ dengan Menggunakan Kulit Pisang Kepok (Musa paradisical Linn), Tesis, Program Pascasarjana, Universitas Hasanuddin, Makasar. 
Hutagalung, H.P., 1989, Mercury and Cadmium Content in Green Mussels,Mytilus Visidis L from Onrust Water, Jakarta Bay, Jakarta. Marganof, 2003, Potensi Limbah Udang sebagai Penyerap Logam Berat (Timbal, Kadmium, Tembaga) di Perairan, Tesis, Pengantar Ke Falsafah Sains Program Pascasarjana S3 IPB, Bogor

Muhammad, M. dan Achmad, S., 1990, Aplikasi Analisis Spektrofotometer UV-Vis, Mecphiso Grafika, Surabaya.

Palar. H., 1994, Pencemaran dan Toksikologi Logam Berat, Rineka Cipta, Jakarta.

Sulfikar, J., dan Ramlawati, 2015, Kapasitas Adsorpsi Arang Aktif Ijuk Pohon Aren (Arenga pinnata) terhadap $\mathrm{Pb}^{2+}$, Jurnal Sainsmat, 4(1): 57-56
Suligundi, B.T., 2013, Penurunan Kadar COD (Chemical Oxygen Demand) Pada Limbah Cair Karet Dengan Menggunakan Reaktor Biosand Filter Yang 39 Dilanjutkan Dengan Reaktor Activated Carbon, Jurnal Teknik Sipil Untan, 13(1): 14-20

Syarief, 2010, Pengaruh Konsentrasi Adsorbat, Temperatur, dan Tegangan Permukaan pada Proses Adsorpsi Gliserol oleh Alumina, Skripsi, Jurusan Kimia, FMIPA, Universitas Sebelas Maret, Surakarta.

Triyana, M., dan Sarma, T., 2003, Arang Aktif (Pengenalan dan Proses Pembuatannya), Skripsi, Jurusan Teknik Industri, Fakultas Teknik, Universitas Sumatera Utara. 